\title{
Nutrient partitioning and fetal growth in rapidly growing adolescent ewes
}

\author{
J. M. Wallace, R. P. Aitken and M. A. Cheyne \\ Rowett Research Institute, Bucksburn, Aberdeen, AB2 9SB, UK
}

\begin{abstract}
A highly controlled model to investigate nutrient partitioning and the control of fetal growth in the rapidly growing adolescent sheep is described. Embryos recovered from superovulated adult ewes inseminated by a single sire were transferred in singleton to the uterus of prepubertal adolescent recipients induced to ovulate at 21 weeks of age (liveweight $44.4 \pm 0.38 \mathrm{~kg}$ ). After embryo transfer, the adolescent recipients were individually offered a high $(n=28)$ or low $(n=20)$ quantity of a complete diet calculated to achieve rapid (RMG) or normal (NMG) maternal growth rates. After day 100 of gestation the feed intake of the NMG group was adjusted weekly to meet the increasing nutrient demands of the gravid uterus. The proportion of adolescent recipients initially conceiving was significantly $(P<0.01)$ influenced by maternal nutrient intake and was lower in the RMG (0.57) than in the NMG (0.85) group. For adolescent dams that maintained their pregnancies, liveweight gain during the first 95 days of gestation was significantly $(P<0.001)$ higher in the RMG compared with the NMG group $(234 \pm 9.5$ and $75 \pm 5.0 \mathrm{~g}$ day $^{-1}$, respectively). Rapid maternal growth rates were associated with a significant reduction in both fetal and placental weights as determined when the animals were killed on day 95 of gestation ( $n=3$ per group) or at term. For the RMG $(n=8)$ and NMG $(n=11)$ groups, respectively, mean lamb birthweights at term were $2.74 \pm 0.25$ and $4.34 \pm 0.27 \mathrm{~kg}$ $(P<0.001)$, while term placental weights were $263 \pm 16.8$ and $438 \pm 44.6 \mathrm{~g}(P<0.002)$. The number of fetal cotyledons per placenta and mean fetal cotyledon weight were significantly lower in RMG compared with NMG ewes $(P<0.05)$. Irrespective of treatment group, lamb birthweight was highly positively correlated with placental weight and both parameters were negatively correlated with maternal liveweight gain during the first 100 days of gestation. The incidence of non-infectious spontaneous abortion at $125 \pm 1.3$ days of gestation was higher $(P<0.001)$ in the RMG (4 of 12$)$ than in the NMG (1 of 12$)$ group. Similarly, duration of gestation for those ewes delivering live young was shorter $(P<0.01)$ in the RMG compared with the NMG group ( $140 \pm 0.94$ versus $143 \pm 0.28$ days). Colostrum yield at parturition was positively related to placental weight and significantly lower $(P<0.001)$ in the RMG than in the NMG group $(35 \pm 12.1$ and $247 \pm 36.2 \mathrm{~g}$, respectively). Neonatal survival rates at $72 \mathrm{~h}$ after parturition were reduced $(P<0.05)$ in the RMG $(38 \%)$ compared with the NMG group $(91 \%)$. These data suggest that in rapidly growing adolescent ewes, the established anabolic drive to maternal tissue synthesis is maintained at the expense of the gradually evolving nutrient requirements of the gravid uterus. This results in a major restriction in placental growth and a highly significant decrease in birthweight.
\end{abstract}

\section{Introduction}

Alterations in the prenatal growth process influence size and
viability at birth. In domestic livestock species, low birthweight
impinges on postnatal growth and productivity (Bell, 1992)
while in humans, recent epidemiological data suggest that there
is a strong association between fetal growth derangement and
the development of a number of health disorders in adult life

Received 5 December 1995.
(Barker $e t$ al., 1993). Our current understanding of the origins and consequences of prenatal growth retardation are largely derived from studies of pregnant sheep (Carter, 1994; Robinson et al., 1994). To date experimental restriction of fetal growth in this species has been achieved by chronic undernutrition (Mellor, 1983), heat stress (Alexander and Williams, 1971; Bell et al., 1987) premating carunclectomy (Alexander, 1964; Robinson et al., 1979) and uterine artery ligation (Emmanoulides et al., 1968). None of these extreme or invasive models mimics the natural restriction of fetal growth known to 
occur in pregnant adolescents. Human adolescent mothers have a high risk of delivering low birthweight and premature infants who die within the first year of life (Dwyer, 1974; Friede et al., 1987; McAnarney, 1987). The risk of adverse adolescent pregnancy outcome appears to be dependent on either the growth status of the mother at the time of conception (Naeye, 1981; Frisancho et al., 1985; Scholl and Hediger, 1993) or her young gynaecological age (Zlatnik and Burmeister, 1977; Scholl et al., 1989). Studies of adolescent pregnant rats have shown that the growth of the dam is maintained at the expense of her progeny, which exhibit a lower growth rate during both pregnancy and lactation than do progeny of adult dams (Hashizume et al, 1991).

The aim of the present study was to investigate nutrient partitioning and fetal growth in rapidly growing versus normally growing pregnant adolescent sheep carrying a singleton fetus and to evaluate whether the growing adolescent ewe has potential as an alternative model for investigating the causes and consequences of prenatal growth restriction.

\section{Materials and Methods}

\section{Animals and experimental design}

Ten adult Border Leicester $\times$ Scottish Blackface (Greyface) ewes were used to donate embryos for transfer into 48 recipient ewe lambs (Suffolk or Dorset Horn $\times$ Greyface) on five separate days at the end of the breeding season (about 11 April). All animals were housed individually under natural lighting conditions at the Rowett Research Institute $\left(57^{\circ} \mathrm{N} 2^{\circ} \mathrm{W}\right)$. The recipient ewe lambs were prepubertal, $146 \pm 1.2$ days old and weighed $44.4 \pm 0.38 \mathrm{~kg}$ (means \pm SEM) at the time of embryo transfer. For donors and recipients, synchronization of oestrus was achieved by withdrawing progestagen impregnated vaginal pessaries $(40 \mathrm{mg}$ fluorogestone acetate, Chronogest; Intervet Ltd, Cambridge) 12 days after their insertion. In donor ewes, multiple ovulations were stimulated by i.m. injection of 1500 iu pregnant mares' serum gonadotrophin (PMSG; Intervet Ltd) $28 \mathrm{~h}$ before pessary withdrawal and a further (i.m.) injection of gonadotrophinreleasing hormone $(\mathrm{GnRH}, 0.008 \mathrm{mg}$ Buserelin: Receptal; Hoechst UK Ltd, Uxbridge) given 20-24 h after pessary withdrawal. For recipient ewe lambs, pessaries were withdrawn $6 \mathrm{~h}$ in advance of pessary withdrawal in the donors and ovulation was stimulated by i.m. administration of 700 iu PMSG. The onset of oestrus was assessed by presenting females to vasectomized rams three times a day and the protocol resulted in good synchrony between donor and recipient animals (onset of overt oestrus, $22.1 \pm 0.69$ and $31.6 \pm 0.76 \mathrm{~h}$ after pessary withdrawal, respectively). Fifty hours after pessary withdrawal donor ewes were inseminated by intrauterine injection under laparoscopic visualization as described by McKelvey et al. (1985). Fresh semen collected by an artificial vagina from a single sire (Dorset Horn) of proven fertility was diluted 1:3 (v:v) with PBS and approximately $0.3 \mathrm{ml}$ of diluted semen was deposited in each horn. Oocytes were recovered from 10 donor ewes at laparotomy on day 3 of the oestrous cycle (day $0=$ insemination) using a standard technique of retrograde flushing of each oviduct (Hunter et al.,
1955). Mean ovulation and embryo recovery rates were $12.3 \pm 2.04$ corpora lutea and $6.6 \pm 1.21$ embryos, respectively. After assessment of developmental stage using a stereomicroscope ( $\times 40$ magnification), embryos were held in fresh ovum culture media until transferred to recipients within $4 \mathrm{~h}$ of recovery. Forty-eight good quality embryos (8-16 cells or loose morulae) were synchronously transferred, in singleton, into the uteri of the recipient ewe lambs. Ovulation rate was recorded and the embryo was transferred into the tip of the uterine horn ipsilateral to the ovary bearing the greater number of corpora lutea. Pregnancy rate was determined by transabdominal ultrasonography at day 60 of gestation.

\section{Nutritional treatments}

For 2 weeks before embryo transfer all ewe lambs were offered sufficient quantities of a complete diet to ensure a liveweight gain of $50-100 \mathrm{~g}$ day $^{-1}$. After embryo transfer, recipient ewe lambs were allocated to one of two dietary treatments on the basis of weight and ovulation rate at the time of transfer. Where possible, care was also taken to randomize for embryo source. The recipients were individually offered either a high or low quantity of a complete diet calculated to achieve rapid (RMG, $n=28$ ) or normal (NMG, $n=20$ ) maternal growth rates. The aim of the latter group was to maintain a moderate growth rate of $50-75 \mathrm{~g}^{\text {day }}{ }^{-1}$ during the first 100 days of gestation. The diet was offered in two equal feeds at 08:00 h and 16:00 h daily and supplied 10.2 MJ metabolizable energy and $137 \mathrm{~g}$ crude protein $\mathrm{kg}^{-1}$. The diet contained $30 \%(\mathrm{w} / \mathrm{v})$ coarsely milled hay, $50 \%$ barley, $10 \%$ molasses, $9 \%$ fishmeal, $0.3 \%$ salt, $0.5 \%$ dicalcium phosphate and $0.2 \%$ of a vitamin-mineral supplement and had an average dry matter of $86 \%$. The low intake recipients were offered their entire ration immediately after transfer, while high intake recipients had the amount of feed offered increased gradually over 2 weeks until the daily feed refusal was approximately $15 \%$ of the total offered, equivalent to ad libitum intakes. The amount of feed offered was reviewed, and adjusted on an individual basis when appropriate, three times a week on the basis of both weight change data (recorded weekly) and the amount of feed refused. After day 100 of gestation the feed intake of the NMG ewes was adjusted weekly on an individual basis to maintain body condition score (based on the criteria of Russel et al., 1969) and meet the increasing nutrient demands of the gravid uterus.

\section{Measurements}

At day 95 of gestation, seven ewes (four RMG and three NMG) were killed by barbiturate overdose and the gravid uterus removed and weighed. The uterus was opened by a dorsal incision and the fetal cotyledons were separated from the maternal caruncles by gentle traction. The fetal membranes were ruptured and the fluid volume measured. The umbilical cord was ligated and cut, and the fetus removed. Fetal weight, crown-rump length and sex were recorded. Fetal cotyledons were dissected from the fetal membranes, weighed and counted. One RMG ewe, which had a mummified fetus in an advanced stage of autolysis, was excluded from further 
analysis. Two normally growing recipients killed at day 40 and 75 of gestation for welfare reasons unrelated to the study (broken leg and twisted bowel), were also excluded from further analysis.

Five ewes spontaneously aborted during the final month of gestation. The aborted fetus was weighed and gross appearance recorded. Fetal and placental tissues, and maternal serum samples (collected both on the day of physical abortion and 2 weeks later) were negative for Toxoplasma gondii, Chlamydia psittaci and border disease.

For the remaining ewes (eight RMG and II NMG) pregnancy outcome was determined at term. Ewes were supervised throughout the delivery period and lamb birthweight was recorded immediately after parturition. After the placenta was delivered it was washed, blotted and weighed. The fetal cotyledons were dissected and counted and their total weight recorded. All lambs received oral antibiotic at birth (Synulox, clavulanate-potentiated amoxycillin; Pfizer Ltd, Kent, $12.5 \mathrm{mg}$ $\mathrm{kg}^{-1}$ bodyweight) followed by oral antibiotic (Clamoxyl, $40 \mathrm{mg}$ amoxycillin per lamb; Pfizer Ltd) at $12 \mathrm{~h}$ intervals from 12 to $48 \mathrm{~h}$ after birth. Colostrum yield was measured before lamb suckling and within 30 min of parturition. Oxytocin was administered i.v. to induce milk let-down (Oxytocin-S, 6 iu per ewe; Intervet Ltd) and the ewe milked by hand until all the available colostrum was stripped from the udder. Colostrum yield was determined by weighing and the colostrum was fed back to the lamb at $50 \mathrm{~cm}^{2} \mathrm{~kg}^{-1}$ bodyweight using a stomach tube. When the colostrum yield failed to meet the requirements of the lamb, synthetic colostrum was substituted (Prolamb; Schering-Plough Animal Health, Welwyn Garden City). If lambs failed to suckle their dams within $8 \mathrm{~h}$ of parturition they received at least two further feeds of colostrum followed by ewe milk replacer (Lamlac; Volac Ltd, Royston, Herts) at intervals of $6 \mathrm{~h}$ via stomach tube or bottle. All low birthweight lambs had access to a heating lamp throughout the early neonatal period and all the normal husbandry precautions for maximizing neonatal survival were taken.

\section{Statistics}

Data were analysed using Student's $t$ test and chi-squared test where appropriate. Correlation analysis was by Pearson's product moment test.

\section{Results}

Birthweight and liveweight, age and ovulation rate at embryo transfer were equivalent in adolescent recipients allocated to the normally growing compared with the rapidly growing groups (Table 1). The proportion of adolescent recipients initially conceiving after embryo transfer was significantly $(P<0.01)$ influenced by maternal intake and was lower in the rapidly growing $(0.57)$ than in the normally growing $(0.85)$ group. Twelve adolescent dams per group were allowed to maintain pregnancies beyond day 100 of gestation, and for these animals the incidence of noninfectious spontaneous abortion, occurring at $125 \pm 1.3$ days of gestation, was higher $(P<0.001)$ in the RMG (4 of 12$)$ than in the NMG group ( 1 of 12). The fetal tissues aborted by the RMG dams exhibited
Table 1. Mean ( \pm SEM) birthweight, liveweight, age and ovulation rate at embryo transfer (ET) in adolescent recipient ewes allocated to the normally growing (NMG) and rapidly growing (RMG) groups

\begin{tabular}{lcr}
\hline Treatment & NMG & RMG \\
\hline Number of recipients & 20 & 28 \\
Birth weight $(\mathrm{kg})$ & $4.7 \pm 0.16$ & $4.8 \pm 0.15$ \\
Liveweight at ET $(\mathrm{kg})$ & $44.2 \pm 0.59$ & $44.6 \pm 0.49$ \\
Age at ET (days) & $145.5 \pm 2.02$ & $146.3 \pm 1.55$ \\
Ovulation rate & $2.2 \pm 0.29$ & $1.8 \pm 0.18$ \\
\hline
\end{tabular}

various degrees of autolysis while the fetus from the NMG ewe was estimated to have died $<24 \mathrm{~h}$ before physical abortion.

Dietary intakes and liveweight changes for those adolescents which maintained their pregnancies to term are shown (Fig. 1). During the first and second trimester of pregnancy dietary intakes were on average 1.7 and 2.3-fold higher in the RMG versus the NMG groups $(P<0.001)$. Although the amount of feed offered to the NMG group was increased during the final 40 days of pregnancy to meet the increasing nutrient demands of the gravid uterus, the amount of feed consumed by the RMG group remained on average 1.4-fold higher than that of the NMG group $(P<0.001)$. By day 35 of gestation, maternal liveweight was significantly higher in the RMG compared with the NMG groups $(51.8 \pm 1.21$ and $45.6 \pm 0.66 \mathrm{~kg}$, respectively, $P<0.001)$ and remained higher throughout gestation. The mean liveweight gain during the first 95 days of gestation for the RMG and NMG groups was $234 \pm 9.5$ and $75 \pm 5.0 \mathrm{~g}^{\text {day }}{ }^{-1}$, respectively $(P<0.001)$. Within nutritional treatment groups, the intake and liveweight changes of the adolescent dams killed on day 95 of gestation or which spontaneously aborted during the final month of gestation were equivalent to those delivering live young at term (data not shown). For those ewes delivering live young, body condition score at day 100 of gestation was significantly lower in the NMG than in the RMG groups (2.1 \pm 0.09 and $2.7 \pm 0.10$ score units). This difference in body condition was maintained up to parturition $(2.1 \pm 0.08$ and $2.7 \pm 0.09$ score units for the NMG and RMG groups, respectively) and more importantly the increase in nutrient intake in the NMG dams ensured that they did not lose body condition during the final 40 days of gestation.

In the small subset of ewes killed on day 95 of gestation, rapid maternal growth rates were associated with a significant reduction $(P<0.05)$ in both fetal and total placental weights (Table 2). The number of uterine caruncles occupied by the placenta was not significantly altered by nutritional treatment and both total and mean fetal cotyledon weight were significantly lower $(P<0.05)$ in the RMG than in the NMG groups.

Pregnancy outcome data for adolescent dams delivering live young at term are presented (Table 3). Rapid maternal growth rates during pregnancy were associated with a significant $(P<0.001)$ decrease in the duration of gestation compared with normally growing dams. In addition, rapid maternal growth during pregnancy resulted in highly significant reductions in 

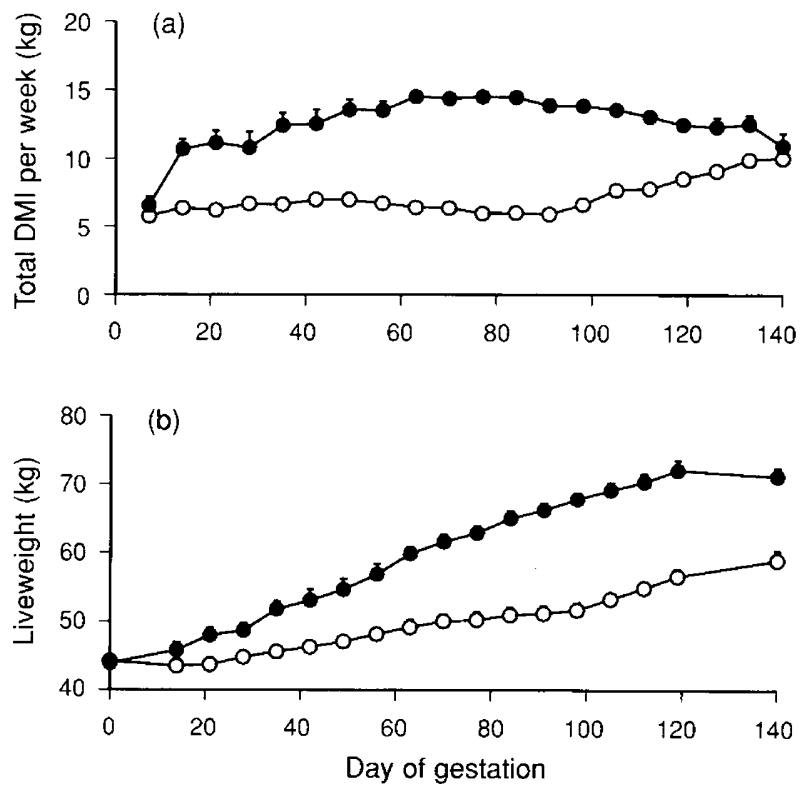

Fig. 1. (a) Weekly dry matter intakes (DMI) and (b) maternal liveweight changes throughout gestation in rapidly (•) and normally (O) growing adolescent dams carrying singleton fetuses to term. Values are means \pm SEM.

both lamb birthweight $(37 \%, P<0.001)$ and total placental weight $(40 \%, P<0.002)$. Complete placental records were obtained for all RMG and for 8 of 11 NMG dams. Relative differences in total placental weight at term were similar to differences measured at day 95 of gestation in both groups. Irrespective of stage of pregnancy, the number of fetal cotyledons per placenta was significantly lower in the RMG than in the NMG groups $(73.7 \pm 5.06$ and $90.7 \pm 5.55$, $P<0.05$, respectively). The individual relationships between placental weight, maternal liveweight gain during the first 100 days of gestation, duration of gestation and birthweight are illustrated (Fig. 2). Irrespective of treatment group, lamb birthweight and total placental weight were positively correlated $(r=0.867, n=16, P<0.001)$ and fetal to placental weight ratios were equivalent between groups (Table 3). The duration of gestation was weakly correlated with birthweight $(r=0.507$, $n=19, P<0.05)$ but not with placental weight $(r=0.443$, $n=16, P>0.05)$. The lamb born at day 135 of gestation was the heaviest born to a RMG dam. Maternal liveweight gain during the first 100 days of gestation was highly negatively correlated with both placental weight at term $(r=-0.678$, $n=16, P<0.01)$ and lamb birthweight $(r=-0.640, n=19$, $P<0.01$ )

Colostrum yield, measured within $30 \mathrm{~min}$ of parturition and before lamb suckling was significantly lower $(P<0.001)$ in the rapidly growing compared with the normally growing dams $(35 \pm 12.1$ and $247 \pm 36.2 \mathrm{~g}$, respectively). Indeed, two animals in the RMG group failed to yield any colostrum in response to exogenous oxytocin administration. Irrespective of dietary treatment, placental weight and colostrum yield were highly positively correlated ( $r=0.731, n=16, P<0.002$, Fig. 3).

One lamb from a normally growing dam died during delivery by caesarian section. All other lambs were delivered vaginally and were vigorous at birth. However, in spite of intensive neonatal care procedures including frequent colostrum administration, five of eight lambs born to rapidly growing dams died within $72 \mathrm{~h}$ of parturition. For these individuals, survival time was positively correlated with duration of gestation $(r=0.922, n=5, P<0.05)$ but not with placental or birth weight.

\section{Discussion}

High nutrient intakes throughout gestation in adolescent sheep resulted in rapid maternal growth rates which were maintained at the expense of the gradually evolving nutrient requirements of the gravid uterus. This resulted in a significant reduction in both placental and fetal growth as determined at day 95 of gestation and at term.

The results of the present study considerably extend previous observations of reproductive performance in adolescent lambs mated at 8 months of age, which reported a tendency for lamb birthweight to decrease in singleton but not twin bearing ewes in response to an increase of crude protein in the diet (Robinson et al., 1971). The dietary treatments in the present study involved varying the amount of both energy and protein, in that the dams received differing amounts of the same diet. The protein and energy requirements of the adolescent ewe have been examined in a large study involving two quantities of energy with three quantities of protein for each quantity of energy, offered from 40 days after mating until parturition (Quirke et al., 1978). Combining data for singleton and twin pregnancies revealed that, for ewes fed the lower energy diet, lamb birthweight tended to increase with increasing protein but that the opposite occurred in ewes fed the higher energy diet. However, these early studies were both confounded by the use of prolific genotypes whose ovulation rate and hence degree of embryo loss were unknown. The use of embryo recovery and transfer techniques in the present study allowed us to investigate nutrient partitioning during singleton pregnancies only. In addition, it was possible to increase the homogeneity of the resulting fetuses by using a single sire and a small number of donor females. Reciprocal embryo transfer studies between adolescent and adult sheep have revealed that embryos derived from adolescent ewes have an inherently low viability following transfer to either an adolescent or adult uterus (Quirke and Hanrahan, 1977; McMillan and McDonald, 1985). The recovery of embryos from adult ewes therefore also allowed us to avoid this potentially confounding variable.

The results of the present study are the first report of placental data for growing adolescent ewes. In sheep, the growth of the placenta has been completed by the end of the third month of gestation, while the fetus has only reached approximately $15 \%$ of its final weight at this stage (Robinson et al., 1977). In the present study, total placental weight was significantly lower in rapidly growing versus normally growing dams by day 95 of gestation. This suggests that high maternal nutrient intakes were influencing the growth of the placenta during early and mid-gestation and that alterations in placental size and, by implication, functional capacity are the primary constraint on fetal growth in the growing adolescent ewe. The number of uterine caruncles and hence cotyledonary 
Table 2. Fetal and placental parameters in normally growing (NMG) and rapidly growing (RMG) adolescent dams killed on day 95 of gestation

\begin{tabular}{|c|c|c|c|c|c|}
\hline Parameter & \multicolumn{2}{|c|}{ NMG } & \multicolumn{2}{|c|}{ RMG } & $\begin{array}{l}\text { Significance } \\
\text { of differences }\end{array}$ \\
\hline Number of pregnant adolescents & \multicolumn{2}{|c|}{3} & \multicolumn{2}{|r|}{3} & \\
\hline \multicolumn{6}{|l|}{ Maternal weight } \\
\hline at embryo transfer $(\mathrm{kg})$ & 45.5 & \pm 1.19 & 47.5 & \pm 1.25 & ns \\
\hline at day 95 of gestation $(\mathrm{kg})$ & 53.8 & $\pm \quad 2.12$ & 75.4 & \pm 3.40 & ** \\
\hline Fetal weight $(\mathrm{g})$ & 817 & \pm 17.3 & 645 & \pm 55.7 & * \\
\hline Total placental weight $(\mathrm{g})$ & 471 & \pm 61.7 & 215 & \pm 43.7 & * \\
\hline Number of fetal cotyledons & 92 & $\pm \quad 6.7$ & 74 & \pm 14.1 & ns \\
\hline Total fetal cotyledon weight $(\mathrm{g})$ & 306 & \pm 35.6 & 121 & \pm 15.5 & $* *$ \\
\hline Mean fetal cotyledon weight per placenta $(\mathrm{g})$ & \multicolumn{2}{|c|}{$3.37 \pm 0.54$} & \multicolumn{2}{|c|}{$1.73 \pm 0.28$} & * \\
\hline Fetal fluid volume (ml) & 1470 & \pm 230 & 1400 & \pm 727 & ns \\
\hline
\end{tabular}

Values are mean \pm SEM.

$* P<0.05, * * P<0.01$, ns: not significant.

Table 3. Mean duration of gestation, lamb birthweight and placental parameters in normally growing (NMG) versus rapidly growing (RMG) adolescent dams

\begin{tabular}{|c|c|c|c|}
\hline Parameter & NMG & RMG & $\begin{array}{l}\text { Significance } \\
\text { of differences }\end{array}$ \\
\hline Number of adolescents & 11 & 8 & \\
\hline $\begin{array}{l}\text { Duration of gestation (days) } \\
\text { (range) }\end{array}$ & $\begin{array}{c}143.1 \pm 0.28 \\
(142-144)\end{array}$ & $\begin{array}{c}140.2 \pm 0.94 \\
(135-143)\end{array}$ & ** \\
\hline $\begin{array}{l}\text { Fetal weight }(\mathrm{kg}) \\
\text { (range) }\end{array}$ & $\begin{array}{l}4.34 \pm 0.27 \\
(2.95-5.90)\end{array}$ & $\begin{array}{l}2.74 \pm 0.25 \\
(1.91-3.92)\end{array}$ & $* * *$ \\
\hline $\begin{array}{l}\text { Total placental weight (g) } \\
\text { (range) }\end{array}$ & $\begin{array}{c}438 \pm 44.6 \\
(260-650)\end{array}$ & $\begin{array}{c}263 \pm 16.8 \\
(188-330)\end{array}$ & $* *$ \\
\hline Number of fetal cotyledons & $90 \pm 7.5$ & $74 \pm 5.4$ & ns \\
\hline Total fetal cotyledon weight $(\mathrm{g})$ & $127 \pm 15.0$ & $63 \pm 8.2$ & $* *$ \\
\hline Mean fetal cotyledon weight per placenta $(\mathrm{g})$ & $1.41 \pm 0.11$ & $0.87 \pm 0.11$ & $* *$ \\
\hline Fetal:placental weight ratio & $9.8 \pm 0.57$ & $10.3 \pm 0.45$ & ns \\
\hline
\end{tabular}

Values are mean \pm SEM.

${ }^{* *} P<0.01, * * * P<0.001$, ns: not sigificant.

attachment sites occupied by the developing trophoblast is fixed by 30 days after conception (Barcroft and Kennedy, 1939). In the present study, combining the data for all ewes revealed that the number of fetal cotyledons per placenta was significantly lower in the rapidly growing than in the normally growing dams, and suggests that the nutritional treatments may have been influencing trophoblast growth and development from a very early stage of pregnancy.

Progesterone plays a major role in controlling maternal secretion of nutrients, growth factors, immunosuppressive agents and enzymes required for successful embryo growth and development. High dietary intakes are inversely related to peripheral progesterone concentrations during early pregnancy in adult sheep (Williams and Cumming, 1982; Wallace et al., 1994) and nutritional effects on embryo survival may operate through progesterone-dependent modifications of endometrial secretory function (Robinson, 1990). Thus, if progesterone falls below a critical threshold during the peri-attachment period, it is probable that the growth of the differentiating conceptus may be compromised, resulting in fewer uterine caruncles being used. While we have not determined whether peripheral progesterone concentrations were lower in the high intake ewes in the present study, it is interesting to note that their initial conception rate was significantly reduced. In addition, within the high intake group, the adolescent recipients that maintained pregnancy had a higher ovulation rate than did those ewes that did not $(2.1 \pm 0.26$ and $1.3 \pm 0.14$ corpora lutea, respectively, $P<0.05$ ).

In carunclectomy studies, surgical removal of potential endometrial implantation sites can result in overgrowth or structural remodelling of the remaining cotyledons to such an extent that placental function and hence fetal growth can be maintained in a proportion of animals (Robinson et al., 1979; Owens et al., 1987a). There was no evidence of a similar compensatory mechanism in the present study in that mean fetal cotyledon weight was significantly lower in rapidly growing than in normally growing dams at both day 95 of gestation and at term. 

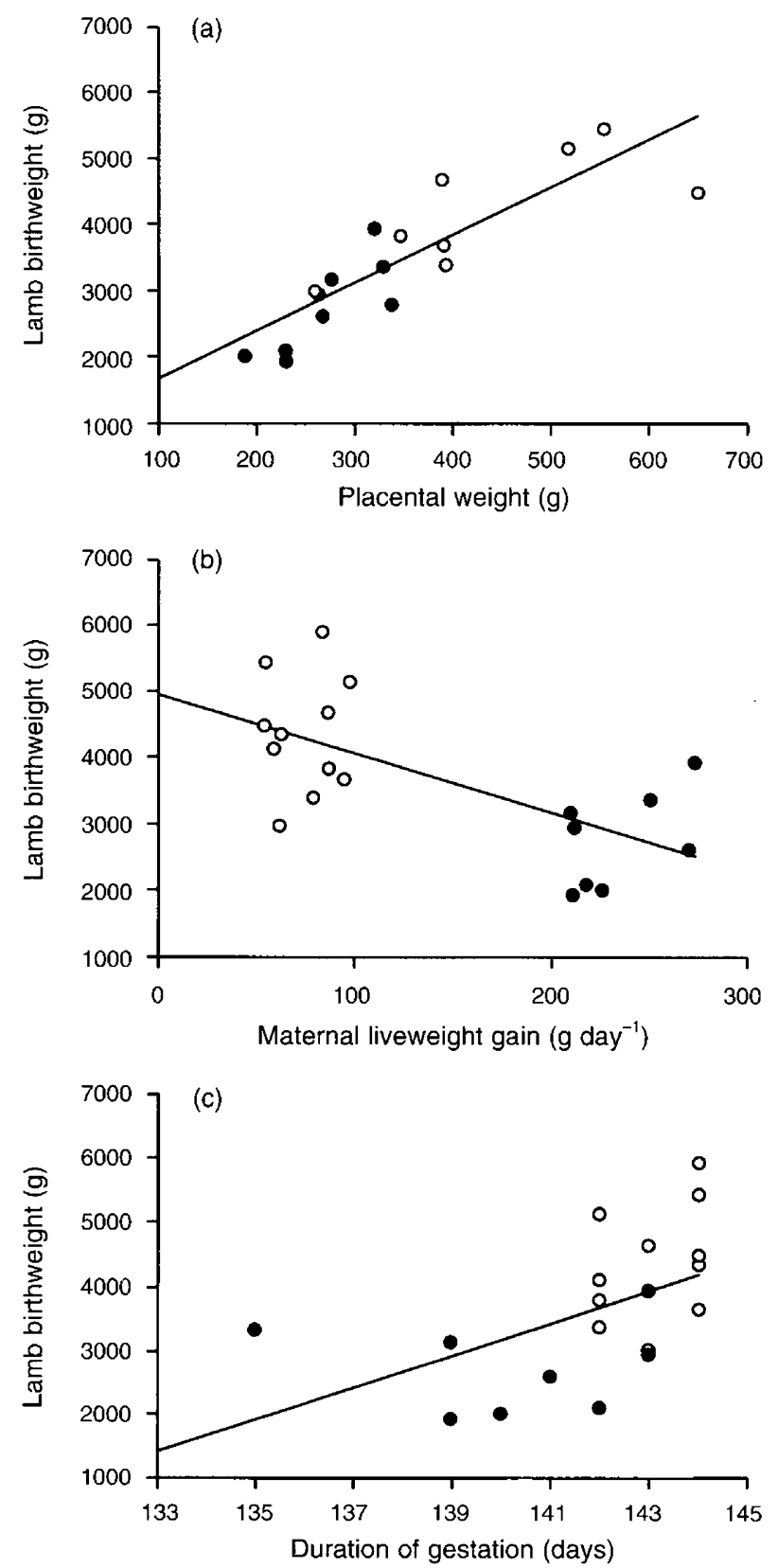

Fig. 2. Relationship between lamb birthweight and (a) total placental weight, (b) maternal liveweight gain up to day 95 of gestation and (c) duration of gestation in rapidly $(\bullet)$ and normally growing $(0)$ adolescent dams carrying singleton fetuses.

In adult ewes, maternal undernutrition during early and mid-gestation has been shown to both enhance (Faichney and White, 1987; McCrabb et al., 1991) and retard (Everitt, 1964; Mellor, 1983; McCrabb et al., 1986) placental growth. This variable response to undernutrition may depend on both the maternal liveweight at mating (McCrabb et al., 1992) and body condition score (Kelly, 1992). In contrast, the two groups of adolescent recipients in the present study were of equivalent liveweight and body condition score at the time of embryo transfer. High dietary intakes were maintained throughout the period of placental growth in the rapidly growing dams but, in

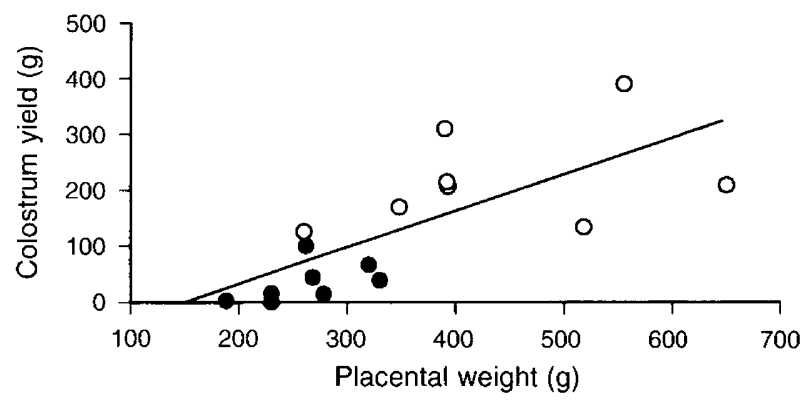

Fig. 3. Relationship between total placental weight and colostrum yield at parturition in rapidly $(\bullet)$ and normally (O) growing adolescent dams delivering singleton fetuses.

spite of ready availability of nutrients, placental mass was highly negatively correlated with liveweight gain during this period. While the factors underlying early placental growth and function in sheep are poorly understood, the growing adolescent may provide a valuable and alternative paradigm to investigate the role of maternal nutrition in early placental growth. Experimental restriction of placental growth is associated with major reductions in uteroplacental blood flow (Bell et al., 1987; Owens et al., 1986). Although not examined in the present study, it is possible that when nutrient intakes are high, blood flow to support maternal tissue synthesis is maintained at the expense of uteroplacental blood flow, resulting in reduced placental growth and functional development.

The suggestion that continuing maternal growth rather than gynaecological immaturity is the major factor limiting fetal growth during human adolescent pregnancy is supported by the present study in that the animals were all prepubertal and of equivalent age when ovulation was induced. In human studies, the use of the knee height measuring device to categorize growing and non-growing adolescents has demonstrated that continuing maternal growth at the time of conception is associated with a significant but modest reduction in birthweight (about $100 \mathrm{~g}$ ) in both primiparous and multiparous mothers (Scholl and Hediger, 1993). Placental parameters have rarely been measured in human studies but Frisancho et al. (1985) reported small reductions in placental weight in still growing adolescent girls and that these were associated with low birthweights. Pregnancy in adolescents < 15 years old at the time of conception is associated with a high incidence of spontaneous abortion (SNAP, 1993), while adolescent pregnancy per se is associated with preterm delivery and poor neonatal prognosis (Zuckerman et al., 1983). In the present study, the significantly higher incidence of spontaneous abortion and shorter duration of gestation in the rapidly growing ewes suggest that insufficient placental growth and hence reduced nutrient transfer may be central to the aetiology of the adverse pregnancy outcomes in both species.

One of the marked differences between nutritional treatment groups in the present study was the reduction in colostrum yield at parturition in the rapidly growing versus the normally growing adolescents. This agrees with a previous study in which adolescent lambs submitted to an accelerated rearing system and then mated at 13-15 months of age had a lower milk yield and fewer mammary alveoli than did adolescents displaying moderate weight gains (Umberger et al., 1985). 
These effects on mammary development appear to be age dependent and are largely programmed during the period of rapid mammary parenchymal growth which occurs before sexual maturity is reached (Johnsson and Hart, 1985). In the present study, the adolescents were only 21 weeks old at the time of ovulation induction and were prepubertal in spite of having reached a liveweight compatible with sexual maturity. Thus it seems plausible that allometric growth of the mammary gland per se may have been compromised in these rapidly growing dams. Along with steroids and thyroid hormones, protein hormones of the prolactin and growth hormone family play a crucial role in stimulating the development, differentiation and function of the mammary gland. Many of these hormones are secreted by the placenta in increasing amounts as pregnancy progresses and are positively correlated with placental and mammary gland weight (Mellor, 1987). Thus, the restriction in placental mass observed in the rapidly growing dams in the present study may have resulted in a lower capacity to secrete placental hormones resulting in a reduction in mammary development and colostrum production. Low neonatal survival rates in the present study prevented us from determining whether low colostrum yield at parturition was predictive of poor lactation performance subsequently. However, cross-fostering of normal and growth retarded rat pups born to adult and adolescent dams has shown that growth rates of pups suckling adolescent mothers are restricted during the first 15 days of lactation (Hashizume et al., 1991).

The low neonatal survival rates of lambs born to rapidly growing adolescents and the positive relationship between survival time and duration of gestation suggest that prematurity was a major cause of neonatal death. These small birthweight neonates were vigorous at birth and routine postmortem analyses failed to reveal a common cause of death. Experimental placental restriction results in hypoxaemia and hypoglycaemia (Owens ef al., 1987b, c) and is associated with alterations in development of the brain, lung and small intestine (Rees et al., 1988, 1991; Avila et al., 1989), all of which could have contributed to neonatal death in the present study.

In conclusion, this preliminary study of nutrient partitioning in pregnant adolescent ewes has shown that in rapidly growing animals on high dietary intakes the anabolic drive to maternal tissue synthesis is maintained at the expense of the gradually evolving nutrient requirements of the gravid uterus. This results in a major restriction in placental growth which leads to a highly significant decrease in birthweight. The growing pregnant adolescent sheep provides a new non-invasive model with which to study the causes and consequences of prenatal growth restriction.

The authors thank J. J. Robinson for formulating the diet used in this study. This work was supported by the Scottish Office Agriculture Environment and Fisheries Department.

\section{References}

Alexander G (1964) Studies on the placenta of the sheep (Ovis aries L.): placenta size Journal of Reproduction and Fertility 7 289-305

Alexander G and Williams D (1971) Heat stress and the development of the conceptus in domestic sheep Journal of Agricultural Science, Cambridge 76 $53-72$
Avila CG, Harding R, Rees S and Robinson PM (1989) Small intestine development in growth retarded fetal sheep Journal of Pediatric Gastroenterology and Nutrition 8 507-515

Barcroft J and Kennedy IA (1939) The distribution of blood flow between the foetus and placenta in sheep Journal of Physiology, London 95 173-186

Barker DJP, Hales CN, Fall CHD, Osmond C, Phipps K and Clark PMS (1993) Type 2 (non-insulin dependent) diabetes mellitus, hypertension and hyperlipidaemia (syndrome X): relation to reduced fetal growth Diabetologia 36 $62-67$

Bell AW (1992) Foetal growth and its influence on postnatal growth and development. In The Control of Fat and Lean Deposition pp 111-127 Eds KN Boormann, PJ Buttery and DB Lindsay. Butterworth-Heinemann Ltd, Oxford

Bell AW, Wilkening RB and Meschia G (1987) Some aspects of placental function in chronically heat-stressed ewes Journal of Developmental Physiology 9 17-29

Carter AM (1994) Animal models in fetal physiology. In Handbook of Laboratory Animal Science Volume II Animal Models pp 77-92 Eds P Svendsen and I Hau. CRC Press, London

Dwyer JF (1974) Teenage pregnancy American Journal of Obstetrics and Gynecology 118 373-376

Emmanoulides GC, Townsend DE and Bauer RA (1968) Effects of single umbilical artery ligation in the lamb fetus Pediatrics 42 919-927

Everitt GC (1964) Maternal undernutrition and retarded foetal development in sheep Nature 201 1341-1342

Faichney GJ and White GA (1987) Effects on maternal nutritional status on fetal and placental growth and on fetal urea synthesis in sheep Australian Journal of Biological Sciences 40 365-377

Friede A, Baldwin W and Rhodes PH (1987) Young maternal age and infant mortality: the role of low birthweight Public Health Report 102 192-199

Frisancho AR, Matos J, Leonard WR and Yaroch LA (1985) Developmental and nutritional determinants of pregnancy outcome among teenagers American Journal of Physical Anthropology 66 247-261

Hashizume K, Ohashi K and Hamajima F (1991) Adolescent pregnancy and growth of progeny in rats Physiology and Behaviour 49 367-371

Hunter GL, Adams CE and Rowson LEA (1955) Interbreed ovum transfer in sheep Journal of Agricultural Science. Cambridge 46 143-149

Johnsson ID and Hart IC (1985) Pre-pubertal mammogenesis in the sheep 1. The effects of level of nutrition on growth and mammary development in female lambs Animal Production 41 323-332

Kelly RW (1992) Nutrition and placental development Proceedings of the Nutrition Society of Australia 17 203-211

McAnarney ER (1987) Young maternal age and adverse neonatal outcome American Journal of Diseases of Children 141 1053-1059

McCrabb GJ, Hosking BJ and Egan AR (1986) Placental size and foetal growth in relation to maternal undernutrition during mid pregnancy Proceedings of the Nutrition Society of Australia 11147

McCrabb GJ, Egan AR and Hosking BJ (1991) Maternal under nutrition during mid-pregnancy in sheep. Placental size and its relationship to calcium transfer during late pregnancy British Journal of Nutrition 65 157-168

McCrabb GJ, Egan AR and Hosking BJ (1992) Maternal under nutrition during mid-pregnancy in sheep: variable effects on placental growth Journal of Agricultural Science, Cambridge 118 127-132

McKelvey WAC, Robinson JJ, Aitken RP and Henderson G (1985) The evaluation of a laparoscopic insemination technique in ewes Theriogenology 24 519-535

McMillan WH and McDonald MF (1985) Survival of fertilised ova from ewe lambs and adult uteri in the uteri of ewe lambs Animal Reproduction Science 8 235-240

Mellor DJ (1983) Nutritional and placental determinants of foetal growth rate in sheep and consequences for the newborn lamb British Veterinary Journal $139307-324$

Mellor DJ (1987) Nutritional effects on the fetus and mammary gland during pregnancy Proceedings of the Nutrition Society 46 249-257

Naeye RL (1981) Teenaged and pre-teenaged pregnancies: consequences of the fetal-maternal competition for nutrients Pediatrics 67 146-150

Owens JA, Falconer J and Robinson JS (1986) Effect of restriction of placental growth on umbilical and uterine blood flows American Journal of Physiology 250 R427-R434

Owens JA, Falconer J and Robinson JS (1987a) Restriction of placental size in sheep enhances the efficiency of placental transfer of antipyrine, 3-O-methyl-D-glucose but not of urea Journal of Developmental Physiology 9 457-464 
Owens JA, Falconer J and Robinson JS (1987b) Effect of restriction of placental growth on fetal and utero-placental metabolism Journal of Developmental Physiology 9 225-238

Owens JA, Falconer J and Robinson JS (1987c) Restriction of placental growth on oxygen delivery to and consumption by the pregnant uterus and fetus Journal of Developmental Physiology 9 137-150

Quirke JF and Hanrahan JP (1977) Comparison of the survival in the uteri of adult ewes of cleaved ova from adult ewes and ewe lambs Journal of Reproduction and Fertility 51 487-489

Quirke JF, Sheehan W and Lawlor MJ (1978) The growth of pregnant female lambs and their progeny in relation to dietary protein and energy during pregnancy Irish Journal of Agricultural Research 17 33-42

Rees S, Bocking AD and Harding R (1988) Structure of the fetal sheep brain in experimental growth retardation Journal of Developmental Physiology 100 $211-224$

Rees S, Ng J, Dickson K, Nicholas T and Harding R (1991) Growth retardation and the development of the respiratory system in fetal sheep Early Human Development 26 13-27

Robinson JJ (1990) Nutrition in the reproduction of farm animals Nutrition Research Reviews 3 253-276

Robinson Jj, Fraser C, Corse EL and Gill JC (1971) Reproductive performance and protein utilization in pregnancy of sheep conceiving at eight months of age Animal Production 13 653-660

Robinson JJ, McDonald I, Fraser C and Crofts RMJ (1977) Studies on reproduction in prolific ewes 1 . Growth of the products of conception Journal of Agricultural Science, Cambridge 88 539-552

Robinson IS, Kingston EJ, Jones CT and Thorburn GD (1979) Studies on experimental growth retardation in sheep. The effect of removal of endometrial caruncles on fetal size and metabolism Journal of Developmental Physiology 1 379-398
Robinson JS, Owens JA and Owens PC (1994) Fetal growth and growth retardation. In Textbook of Fetal Physiology pp 83-94 Eds GD Thorburn and $R$ Harding. Oxford University Press, Oxford

Russel AJF, Doney JM and Gunn RG (1969) Subjective assessment of body fat in live sheep Journal of Agricultural Science, Cambridge 72 451-454

Scholl TO and Hediger ML (1993) A review of the epidemiology of nutrition and adolescent pregnancy: maternal growth during pregnancy and its effect on the fetus Journal of the American College of Nutrition 12 101-107

Scholl, TO, Hediger ML, Salmon RW, Belsky DH and Ances IG (1989) Association between low gynaecological age and preterm birth Paediatric and Perinatology Epidemiology 3 357-366

Scottish Needs Assessment Programme (1994) Teenage pregnancy in Scotland - report Scottish Forum for Public Health Medicine pp 3-4

Umberger SH, Goode I, Caruolo EV, Harvey RW, Britt JH and Linnerud AC (1985) Effects of accelerated growth during rearing on reproduction and lactation in ewes lambing at 13 to 15 months of age Theriogenology 23 555-564

Wallace JM, Aitken RP and Cheyne MA (1994) Effect of post-ovulation nutritional status in ewes on early conceptus survival and growth in vivo and luteotrophic protein secretion in vitro Reproduction Fertility and Development 6 $253-259$

Williams AH and Cumming IA (1982) Inverse relationship between concentration of progesterone and nutrition in ewes Journal of Agricultural Science, Cambridge 98 517-522

Zlatnik FJ and Burmeister LF (1977) Low gynecological age: an obstetric risk factor American Journal of Obstetrics and Gynecology 128 183-186

Zuckerman B, Alpert JJ, Dooling E, Hingson R, Kayne H, Morelock S and Oppenheimer E (1983) Neonatal outcome: is adolescent pregnancy a risk factor? Pediatrics 71 489-493 